University of Wollongong

Research Online

Faculty of Engineering and Information

Faculty of Engineering and Information

Sciences - Papers: Part A

Sciences

$1-1-2013$

\title{
Additive-free synthesis of 3D porous V205 hierarchical microspheres with enhanced lithium storage properties
}

Chaofeng Zhang

University of Wollongong, czhang@uow.edu.au

Zhixin Chen

University of Wollongong, zchen@uow.edu.au

Zaiping Guo

University of Wollongong, zguo@uow.edu.au

Xiong Wen Lou

Nanyang Technological University

Follow this and additional works at: https://ro.uow.edu.au/eispapers

Part of the Engineering Commons, and the Science and Technology Studies Commons

Research Online is the open access institutional repository for the University of Wollongong. For further information contact the UOW Library: research-pubs@uow.edu.au 


\title{
Additive-free synthesis of 3D porous V205 hierarchical microspheres with enhanced lithium storage properties
}

\author{
Abstract \\ A facile synthesis of novel 3D porous V2O5 hierarchical microspheres has been developed, based on an \\ additive-free solvothermal method and subsequent calcination. Due to their unique structure, these V205 \\ microspheres display a very stable capacity retention of $130 \mathrm{~mA} \mathrm{~h} \mathrm{~g} \mathrm{(1)} \mathrm{over} 100$ cycles at a current rate \\ of $0.5 \mathrm{C}$, and show excellent rate capability with a capacity of $105 \mathrm{~mA} \mathrm{~h} \mathrm{~g} \mathrm{(1)} \mathrm{even} \mathrm{at} \mathrm{the} 30 \mathrm{C}$ rate. The \\ good electrochemical performance suggests that this unique hierarchical V205 material could be a \\ promising candidate as a cathode material for lithium-ion batteries.

\section{Keywords} \\ additive, free, synthesis, 3d, porous, storage, v2o5, properties, hierarchical, microspheres, enhanced, \\ lithium

\section{Disciplines} \\ Engineering | Science and Technology Studies

\section{Publication Details} \\ Zhang, C., Chen, Z., Guo, Z. \& Lou, X. Wen. (2013). Additive-free synthesis of 3D porous V205 hierarchical \\ microspheres with enhanced lithium storage properties. Energy \& Environmental Science, 6 (3), 974-978.
}




\title{
Additive-free synthesis of 3D porous $\mathrm{V}_{2} \mathrm{O}_{5}$ hierarchical microspheres with enhanced lithium storage properties
}

\author{
Chaofeng Zhang, ${ }^{a, b, c}$ Zhixin Chen, ${ }^{a}$ Zaiping Guo ${ }^{* a, c}$ and Xiong Wen (David) Lou ${ }^{* b}$ \\ Received (in $X X X, X X X) X$ th $X X X X X X X X X 20 X X$, Accepted Xth $X X X X X X X X X 20 X X$ \\ ${ }_{5}$ DOI: 10.1039/b000000x
}

\begin{abstract}
A facile synthesis of novel 3D porous $\mathrm{V}_{2} \mathrm{O}_{5}$ hierarchical microspheres has been developed, based on an additive-free solvothermal method and subsequent calcination. Due to their unique structure, these $\mathrm{V}_{2} \mathrm{O}_{5}$ microspheres display a very stable capacity retention of $130 \mathrm{~mA} \mathrm{~h} \mathrm{~g}^{-1}$ over 100 cycles at a current rate of $0.5 \mathrm{C}$, and show excellent rate capability with a capacity of $105 \mathrm{~mA} \mathrm{~h} \mathrm{~g}^{-1}$ even at the $30 \mathrm{C}$-rate. The good 10 electrochemical performance suggests that this unique hierarchical $\mathrm{V}_{2} \mathrm{O}_{5}$ material could be a promising candidate as a cathode material for lithium-ion batteries.
\end{abstract}

\section{Introduction}

Lithium-ion batteries (LIBs), currently the predominant power source for portable electronics, are continuing to attract great

15 interest as the promising power source for electric vehicles (EVs) and hybrid electric vehicles (HEVs), owing to their high energy density and long lifespan. ${ }^{1,2}$ Their commercial use in EVs, however, is still hindered by their low power density and poor rate performance. ${ }^{2}$ To meet the demands for use in EVs and 20 HEVs, substantial efforts have been dedicated to finding new competitive electrode materials and new structures. ${ }^{1-4}$

Among the potential cathode materials, $\mathrm{V}_{2} \mathrm{O}_{5}$ has been intensively studied in recent years for application in LIBs, due to its high energy density, ease of synthesis, and low cost. ${ }^{5-10} \mathrm{~V}_{2} \mathrm{O}_{5}$ 25 still suffers, however, from low electric conductivity $\left(10^{-2}\right.$ to $10^{-3}$ $\mathrm{S} \mathrm{cm}{ }^{-1}$ ), poor structural stability, and a low $\mathrm{Li}^{+}$ion diffusion coefficient $\left(\sim 10^{-12} \mathrm{~cm}^{2} \mathrm{~s}^{-1}\right)$, resulting in limited long-term cycling stability. ${ }^{11}$ In recent years, various structures reported with different performance suggest that the characteristics of $\mathrm{V}_{2} \mathrm{O}_{5}$, 30 such as the dimensions, morphology, porosity, and texture, are critically important to the electrochemical performance of the electrodes. ${ }^{5,}{ }^{12-17}$ In particular, $\mathrm{V}_{2} \mathrm{O}_{5}$ nanostructures (such as nanotubes, nanofibers, nanoparticles, nanowires, nanorods, and mesoporous structures) have been demonstrated effective to 35 improve the electrochemical kinetics, shorten the diffusion distance for $\mathrm{Li}^{+}$ions, and buffer the volume change during the lithium insertion and extraction processes, as compared with nonnanostructured materials. 5, 10, 12, 16, 18 Nevertheless, dispersed nanoparticles may only give very low volumetric energy density, 40 which makes them unsuitable for LIBs in EVs and other largescale applications. ${ }^{15}$ Additionally, some undesirable side reactions or poor thermal stability can emerge due to the extended contact between the electrolyte and the nanosized materials with large surface area, leading to safety hazards and poor cycling 45 stability. ${ }^{19,20}$ Generally, the method of using microsized spherical particles is one possible approach towards high packing density and decreasing the polarization of the electrolyte in the active layer. ${ }^{9,} 15,21-26$ By comparing the response of micro and nano $\mathrm{LiMn}_{0.85} \mathrm{Fe}_{0.15} \mathrm{PO}_{4}$ based electrodes, Sun et al. have clearly 50 demonstrated that the former, due to its compact configuration, largely surpasses the latter in terms of volumetric energy density and rate capability. ${ }^{20}$ The ordered superstructures, which are selfassembled and transformed from nanostructures, not only maintain the nanostructural features, but also avoid some side-

55 effects common to nanostructures such as low volumetric energy density and poor thermal stability. ${ }^{19,20}$ Recently, the electrode materials with these structures have been found to be the most suitable for improving the electrochemical performance of LIBs. ${ }^{15}$, $21,27-30$ It is therefore highly desirable to prepare 60 microsized $\mathrm{V}_{2} \mathrm{O}_{5}$ spherical structures composed of nanostructures for the design of high-performance LIBs with both high volumetric energy density and high gravimetric energy density, as well as good rate capability.

In this work, we report a facile additive-free solvothermal 65 method followed by a calcination process for mass production of $\mathrm{V}_{2} \mathrm{O}_{5}$ microspheres consisting of porous nanofibers. When evaluated as a cathode material for LIBs, the three-dimensional (3D) porous $\mathrm{V}_{2} \mathrm{O}_{5}$ microspheres manifest significantly improved electrochemical performance in terms of specific capacity, 70 cycling stability, and rate capability.

\section{Results and discussion}

The detailed preparation process for the $\mathrm{V}_{2} \mathrm{O}_{5}$ microspheres $\left(\mathrm{V}_{2} \mathrm{O}_{5}-\mathrm{ms}\right)$ can be found in the Electronic Supplementary Information (ESI). The precursor of $\mathrm{V}_{2} \mathrm{O}_{5}$-ms was first prepared 75 by a solvothermal method, and then heated to obtain the porous structure of $\mathrm{V}_{2} \mathrm{O}_{5}$-ms. $\mathrm{V}_{2} \mathrm{O}_{5}$ nanoparticles $\left(\mathrm{V}_{2} \mathrm{O}_{5}\right.$-np) were also synthesized by a similar procedure but with a longer reaction time. The crystal phase of both $\mathrm{V}_{2} \mathrm{O}_{5}$ samples is first confirmed by their X-ray diffraction (XRD) patterns, as shown in Fig. 1A 80 with the peaks labeled, which demonstrates that all the reflections of the samples are in good agreement with the standard pattern of 

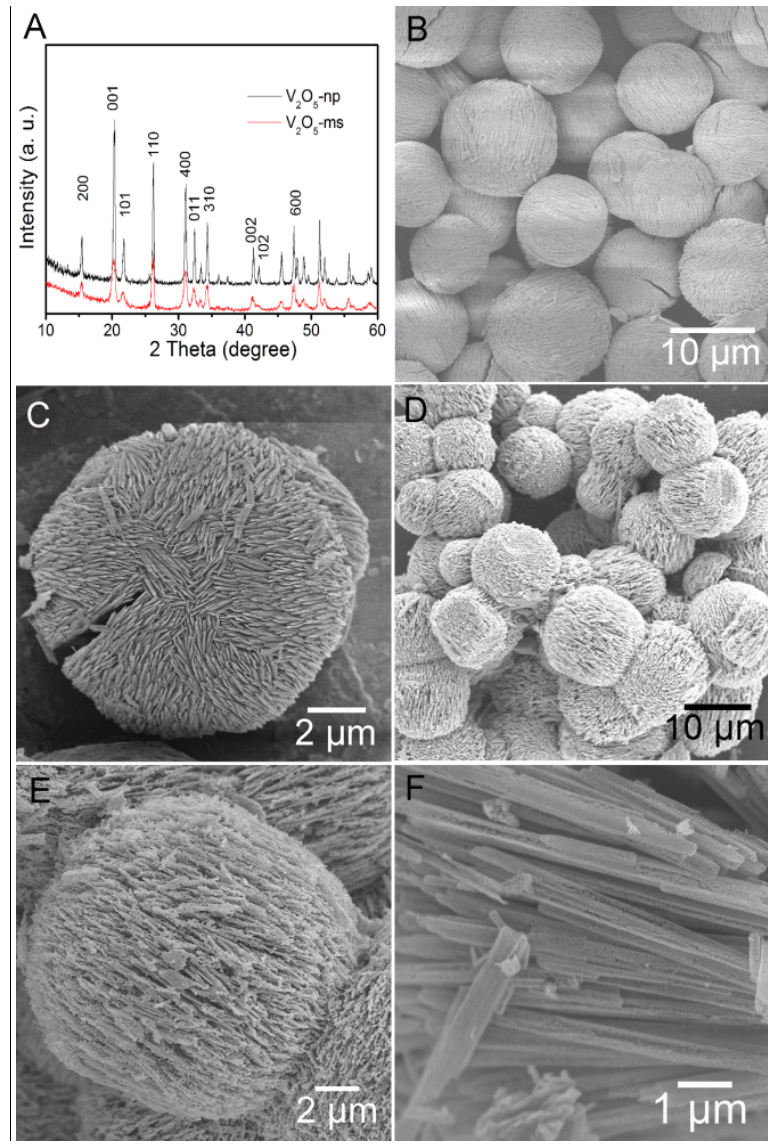

Fig. 1 (A) $\mathrm{X}$-ray diffraction patterns of $\mathrm{V}_{2} \mathrm{O}_{5}$-np and $\mathrm{V}_{2} \mathrm{O}_{5}$-ms. FESEM images of the precursor of $\mathrm{V}_{2} \mathrm{O}_{5}-\mathrm{ms}(\mathrm{B}, \mathrm{C}), \mathrm{V}_{2} \mathrm{O}_{5}$-ms $(\mathrm{D}, \mathrm{E})$, and $\mathrm{V}_{2} \mathrm{O}_{5}-\mathrm{np}$ (F).

5 pure orthorhombic $\mathrm{V}_{2} \mathrm{O}_{5}$ phase (JCPDS card no. 89-0612). No other phases or impurities are detected in the patterns. The morphologies of the two samples are then studied by fieldemission scanning electron microscope (FESEM). As shown in Fig. $1 \mathrm{~B}$, the as-prepared precursor of $\mathrm{V}_{2} \mathrm{O}_{5}-\mathrm{ms}$ consists of 10 microspheres with good uniformity and a diameter of about 4-10 $\mu \mathrm{m}$. The high magnification image of a single sphere presented in Fig. 1C shows that the sphere is composed of uniform nanofibers. After the calcination process, the structure of the microspheres is perfectly retained (Fig. 1D), while the nanoporous structure of the 15 nanofibers arises from the decomposition of the precursor. As shown in Fig. 1E, the 3D microspheres are constructed from these nanoporous fibers. This will endow the material with shorter diffusion pathways and easier $\mathrm{Li}^{+} /$electron transport, leading to enhanced electrochemical performance. A FESEM image of ${ }_{20} \mathrm{~V}_{2} \mathrm{O}_{5}$-np obtained with an extended solvothermal reaction time of $24 \mathrm{~h}$ is shown in Fig. 1F. It can be observed that the microsphere structure is damaged and porous fibers with a length of several micrometers are loosely distributed over a large domain. In a high-magnification FESEM image, it is easily observed that the

${ }_{25} \mathrm{~V}_{2} \mathrm{O}_{5}$-np fibers consist of nanoparticles with a diameter of 40-100 $\mathrm{nm}$, as indicated in Fig. S1 (see ESI).

The formation of the $\mathrm{V}_{2} \mathrm{O}_{5}$-np and $\mathrm{V}_{2} \mathrm{O}_{5}$-ms nanostructures is further evidenced by transmission electron microscope (TEM) observations. The primary particle size of $\mathrm{V}_{2} \mathrm{O}_{5}$-np (Fig. 2A) is in 30 the range of 40-100 nm, while that of $\mathrm{V}_{2} \mathrm{O}_{5}$-ms (Fig. 2B) can be as small as $5-20 \mathrm{~nm}$. In addition, Brunauer-Emmett-Teller (BET)

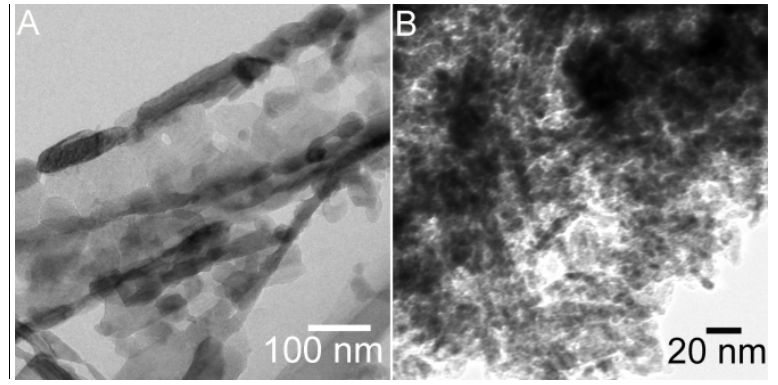

Fig. 2 TEM images of $\mathrm{V}_{2} \mathrm{O}_{5}-\mathrm{np}(\mathrm{A})$ and $\mathrm{V}_{2} \mathrm{O}_{5}-\mathrm{ms}$ (B).

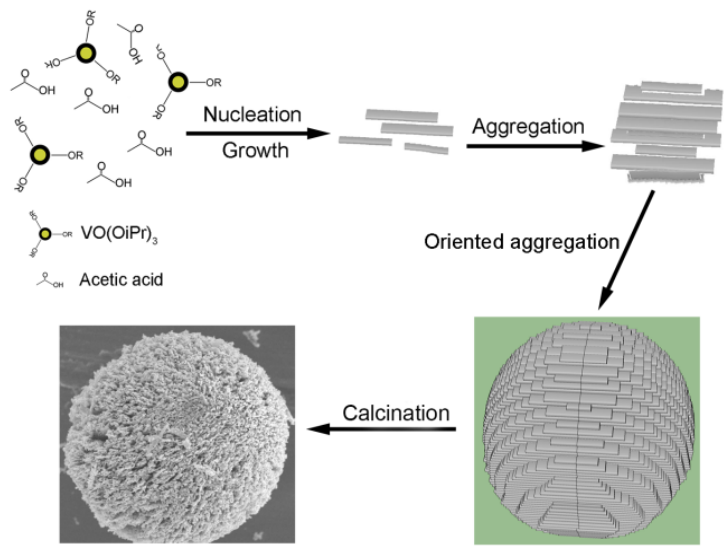

35 Fig. 3 Schematic illustration of the formation of $3 \mathrm{D}$ porous $\mathrm{V}_{2} \mathrm{O}_{5}$ hierarchical microspheres.

measurements show that the specific surface area of $\mathrm{V}_{2} \mathrm{O}_{5}$-ms and $\mathrm{V}_{2} \mathrm{O}_{5}$-np is 41.6 and $29.2 \mathrm{~m}^{2} \mathrm{~g}^{-1}$, respectively.

It was reported that nanostructured materials can grow into 40 self-assembled microstructures based on an oriented aggregation mechanism. ${ }^{31-34}$ Fig. 3 illustrates the proposed growth process for the synthesis of $3 \mathrm{D}$ porous $\mathrm{V}_{2} \mathrm{O}_{5}$-ms, involving the following four steps: (1) nucleation and growth. In the solvothermal process, the overall reaction of vanadium $(\mathrm{V})$ oxytriisopropoxide $\left(\mathrm{VO}(\mathrm{OiPr})_{3}\right)$ 45 and acetic acid (HAc) leads to formation of ROVOOR' $(\mathrm{R}=\mathrm{H}$ or $\mathrm{CH}_{3} \mathrm{CO} ; \mathrm{R}^{\prime}=\left(\mathrm{CH}_{3}\right)_{2} \mathrm{CH}$ or $\left.\mathrm{H}\right)$, according to the following reactions: ${ }^{31}$

$$
\begin{gathered}
\mathrm{VO}(\mathrm{OiPr})_{3}+\mathrm{xCH}_{3} \mathrm{COOH} \rightarrow\left(\mathrm{CH}_{3} \mathrm{COO}\right)_{\mathrm{x}} \mathrm{VO}(\mathrm{OiPr})_{3-\mathrm{x}}+ \\
\mathrm{x}\left(\mathrm{CH}_{3}\right)_{2} \mathrm{CHOH} \\
\mathrm{CH}_{3} \mathrm{COOH}+\left(\mathrm{CH}_{3}\right)_{2} \mathrm{CHOH} \rightarrow \mathrm{CH}_{3} \mathrm{COOCH}\left(\mathrm{CH}_{3}\right)_{2}+\mathrm{H}_{2} \mathrm{O} \\
=\mathrm{VO}-\mathrm{OR}+\mathrm{H}_{2} \mathrm{O} \rightarrow=\mathrm{VO}-\mathrm{OH}+\mathrm{ROH} \\
\left(\mathrm{R}=\mathrm{CH}_{3} \mathrm{CO} \text { or }\left(\mathrm{CH}_{3}\right)_{2} \mathrm{CH}\right) \\
=\mathrm{VO}-\mathrm{OR}+=\mathrm{VO}-\mathrm{OR}^{\prime} \rightarrow=\mathrm{VO}-\mathrm{O}-\mathrm{VO}=+\mathrm{R}-\mathrm{O}-\mathrm{R}^{\prime} \\
\left(\mathrm{R}=\mathrm{H} \text { or } \mathrm{CH}_{3} \mathrm{CO} ; \mathrm{R}^{\prime}=\mathrm{H} \text { or }\left(\mathrm{CH}_{3}\right)_{2} \mathrm{CH}\right)
\end{gathered}
$$

${ }_{55} \mathrm{VO}(\mathrm{OiPr})_{3}$ will first react with $\mathrm{HAc}$ to produce unstable vanadium acetate complexes $\left(\mathrm{CH}_{3} \mathrm{COO}\right)_{\mathrm{x}} \mathrm{VO}(\mathrm{OiPr})_{3-\mathrm{x}}$ by ligand exchange/substitution (eq. 1). Afterwards, water will be synthesized by the reaction between isopropanol and HAc (eq. 2). Then, due to the hydrolysis-condensation and nonhydrolytic 60 condensation processes, V-O-V bonds would form (eq. 3 and 4). During the reaction, numerous precursor nuclei form quickly and then grow into fiber-like nanocrystals, as shown in the FESEM image of the intermediate product after solvothermal reaction for 
5 min (Fig. S2, see ESI). (2) After that, driven by minimization of the overall surface energy, these fiber-like nanocrystals selfaggregate and form microstructured spheres or fan-like structures. ${ }^{33,34}$ As shown in Fig. S3 (see ESI), fan-like bundles of 5 the precursor can be observed after prolonging the reaction time to about $15 \mathrm{~min}$. (3) Oriented aggregation. With longer reaction time, the precursors further aggregate and develop into microsized spheres composed of nanofibers (Fig. S4, see ESI). (4) During the calcination process, the precursors decompose to 10 form the porous $\mathrm{V}_{2} \mathrm{O}_{5}$ structure.
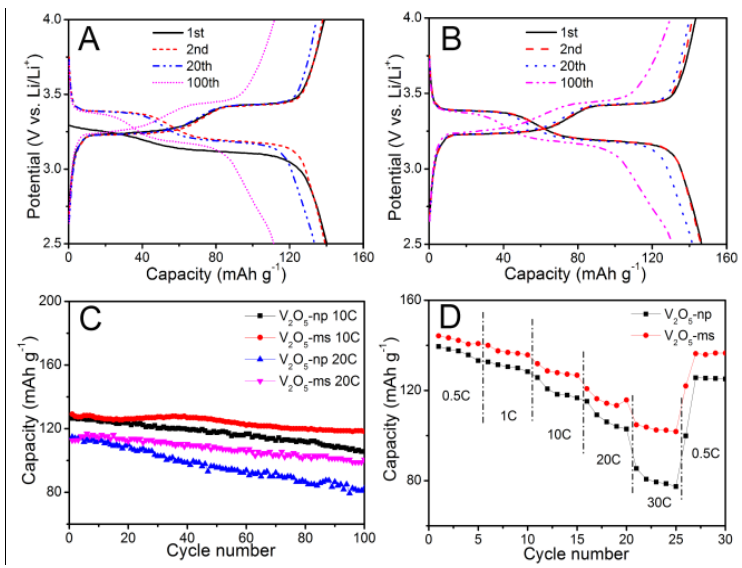

Fig. 4 Charge-discharge voltage profiles of $\mathrm{V}_{2} \mathrm{O}_{5}$-np (A) and $\mathrm{V}_{2} \mathrm{O}_{5}$-ms (B) at the current rate of $0.5 \mathrm{C}$ for the selected cycles indicated. (C) Cycling performance of $\mathrm{V}_{2} \mathrm{O}_{5}$-np and $\mathrm{V}_{2} \mathrm{O}_{5}$-ms at different current rates (10 C and 1520 C). (D) Rate capability of $\mathrm{V}_{2} \mathrm{O}_{5}-\mathrm{np}$ and $\mathrm{V}_{2} \mathrm{O}_{5}$-ms at various current rates.

To demonstrate the possible structural advantages, we have evaluated the electrochemical lithium storage properties of the two samples as cathode materials for LIBs. Fig. 4A shows 20 representative discharge/charge voltage profiles of the $\mathrm{V}_{2} \mathrm{O}_{5}$-np at a current rate of $0.5 \mathrm{C}\left(75 \mathrm{~mA} \mathrm{~g}^{-1}\right)$ within a cut-off voltage window of 2.5-4.0 V, which are in good agreement with previous reports. ${ }^{7,8,14}$ The first discharge of the $\mathrm{V}_{2} \mathrm{O}_{5}$-np electrode is found to be $140.3 \mathrm{~mA} \mathrm{~h} \mathrm{~g}^{-1}$. As shown in Fig. 4B, the $\mathrm{V}_{2} \mathrm{O}_{5}-\mathrm{ms}$ 25 electrode shows similar plateaus, but exhibits a larger capacity in the first cycle compared to $\mathrm{V}_{2} \mathrm{O}_{5}$-np. Specifically, the first discharge capacity is $146.3 \mathrm{~mA} \mathrm{~h} \mathrm{~g}^{-1}$, which reaches nearly its theoretical capacity for the transformation from $\mathrm{V}_{2} \mathrm{O}_{5}$ to $\mathrm{LiV}_{2} \mathrm{O}_{5}$ $\left(147 \mathrm{~mA} \mathrm{~h} \mathrm{~g}^{-1}\right)$.

30 The cycling performance of the $\mathrm{V}_{2} \mathrm{O}_{5}$-np and $\mathrm{V}_{2} \mathrm{O}_{5}$-ms at a current rate of $0.5 \mathrm{C}$ is shown in Fig. S5 (see ESI). The $\mathrm{V}_{2} \mathrm{O}_{5}$-np sample shows relatively stable capacity retention, although the capacity drops to $111 \mathrm{~mA} \mathrm{~h} \mathrm{~g}^{-1}$ at the end of the $100^{\text {th }}$ cycle. The $\mathrm{V}_{2} \mathrm{O}_{5}$-ms sample shows significantly improved cycling 35 performance under the same conditions, as illustrated by its stable capacity retention of $130 \mathrm{~mA} \mathrm{~h} \mathrm{~g}$ after 100 cycles. The cycling performance of the two materials was also investigated at current rates of $10 \mathrm{C}$ and $20 \mathrm{C}$, as shown in Fig. $4 \mathrm{C}$. When the current rate is increased to $10 \mathrm{C}$, the capacity retention of $\mathrm{V}_{2} \mathrm{O}_{5}$-ms upon 40 prolonged cycling is significantly improved over that of $\mathrm{V}_{2} \mathrm{O}_{5}$-np. A high reversible capacity of $118 \mathrm{~mA} \mathrm{~h} \mathrm{~g}^{-1}$ is retained after 100 cycles, which corresponds to a capacity loss of only $0.085 \%$ per cycle, while the $\mathrm{V}_{2} \mathrm{O}_{5}$-np electrode suffers a capacity fading rate of $0.165 \%$ per cycle. Upon further increasing the current rate to ${ }_{45} 20 \mathrm{C}$, a capacity of $113 \mathrm{~mA} \mathrm{~h} \mathrm{~g}^{-1}$ can still be delivered for $\mathrm{V}_{2} \mathrm{O}_{5^{-}}$ $\mathrm{ms}$ initially, and the capacity is as high as $101 \mathrm{~mA} \mathrm{~h} \mathrm{~g}^{-1}$ at the end of the $100^{\text {th }}$ cycle. In contrast, the discharge capacity of $\mathrm{V}_{2} \mathrm{O}_{5}-\mathrm{np}$ drops dramatically from 114 to $82 \mathrm{~mA} \mathrm{~h} \mathrm{~g}^{-1}$. The relevant volumetric capacity at $20 \mathrm{C}$ is presented in Fig. S6 (see ESI). It 50 can be observed that the $\mathrm{V}_{2} \mathrm{O}_{5}$-ms electrode exhibits significantly higher volumetric capacity with excellent cycling stability compared to the $\mathrm{V}_{2} \mathrm{O}_{5}$-np electrode. Additionally, the rate capability of $\mathrm{V}_{2} \mathrm{O}_{5}$-ms is also much better than that of $\mathrm{V}_{2} \mathrm{O}_{5}-\mathrm{np}$, as demonstrated in Fig. 4D. With the benefits of its unique 55 structures, the $\mathrm{V}_{2} \mathrm{O}_{5}$-ms sample exhibits excellent cycling response to a continuously varying current rate. Even when cycled at the very high rate of $30 \mathrm{C}$, a high capacity of $105 \mathrm{~mA} \mathrm{~h}$ $\mathrm{g}^{-1}$ can still be maintained, as shown in Fig. 4D, while a capacity of only $75 \mathrm{~mA} \mathrm{~h} \mathrm{~g}^{-1}$ is delivered by the $\mathrm{V}_{2} \mathrm{O}_{5}$-np sample under the 60 same conditions. After the deep cycling at $30 \mathrm{C}$, the $\mathrm{V}_{2} \mathrm{O}_{5}$-ms material can recover nearly the same initial capacity when the current rate is reduced back to $0.5 \mathrm{C}$. Obviously, the $\mathrm{V}_{2} \mathrm{O}_{5}$-ms sample exhibits higher capacity at each current rate. The electrochemical performance of the $\mathrm{V}_{2} \mathrm{O}_{5}$-ms electrodes is good ${ }_{65}$ compared to that of many published $\mathrm{V}_{2} \mathrm{O}_{5}$ electrodes, in terms of high-rate capability and cycling performance (Table S1, see ESI). To investigate the effects of the unique structure on the conductivity, electrochemical impedance spectroscopy (EIS) measurements (Fig. S7, see ESI) were carried out. The charge70 transfer resistance $\mathrm{R}_{\mathrm{ct}}$ for $\mathrm{V}_{2} \mathrm{O}_{5}-\mathrm{ms}\left(46 \Omega \mathrm{cm}^{-2}\right)$ is less than $70 \%$ of that for $\mathrm{V}_{2} \mathrm{O}_{5}-\mathrm{np}\left(73 \Omega \mathrm{cm}^{-2}\right)$, indicating enhanced charge transfer in the $\mathrm{V}_{2} \mathrm{O}_{5}$-ms electrode. The better performance of $\mathrm{V}_{2} \mathrm{O}_{5}$-ms is also likely due to the unique structural features. Apparently, the porous nanostructure with high surface area is 75 favourable for alleviating the volume change during charging/discharging processes, as well as for increasing the amount of reactive sites and electrode-electrolyte interface. The hierarchical porous structure thus not only facilitates the kinetics for $\mathrm{Li}^{+}$ion diffusion and electron transport by shortening the 80 diffusion pathways to the nanoscale, but also improves the electrode stability because of the reduced lattice strain associated with lithium intercalation. ${ }^{35}, 36$ Moreover, the structural robustness of the $\mathrm{V}_{2} \mathrm{O}_{5}$ microspheres is also perhaps responsible for the improved electrochemical performance. ${ }^{14,20}$

\section{${ }_{85}$ 3. Conclusions}

We have successfully prepared $3 \mathrm{D}$ porous $\mathrm{V}_{2} \mathrm{O}_{5}$ hierarchical microspheres on a large scale by an additive-free solvothermal method followed by annealing at $350{ }^{\circ} \mathrm{C}$ in air. The assynthesized $\mathrm{V}_{2} \mathrm{O}_{5}$ microspheres are composed of well-defined 90 porous nanofibers that arrange themselves in an oriented manner and form a highly porous hierarchical structure. Such porous microspheres give rise to high surface area and high volumetric energy density. Meanwhile, the electronic/ionic transport and the ability to buffer the volume variation are also improved due to the 95 unique porous structure of the microspheres. When evaluated as a cathode material for lithium-ion batteries, the $\mathrm{V}_{2} \mathrm{O}_{5}$ microspheres display relatively stable capacity retention at different current rates. They also show excellent rate capability, with a capacity of $105 \mathrm{~mA} \mathrm{~h} \mathrm{~g}^{-1}$ at the $30 \mathrm{C}$-rate. The excellent electrochemical 100 performance suggests that these unique hierarchical $\mathrm{V}_{2} \mathrm{O}_{5}$ microspheres could be a promising cathode material for lithiumion batteries. 


\section{Acknowledgments}

Financial support provided by the Australian Research Council (ARC) through an ARC Discovery project (DP1094261) is gratefully acknowledged. The authors would also like to thank 5 the Electron Microscopy Centre (EMC) at the University of Wollongong for the electron microscopy characterization.

\section{Notes and references}

a School of Mechanical, Materials \& Mechatronics Engineering, University of Wollongong, NSW 2500, Australia. Email: 10 zguo@uow.edu.au

$b$ School of Chemical and Biomedical Engineering, Nanyang Technological University, 62 Nanyang Drive, Singapore, 637459. Email: xwlou@ntu.edu.sg

${ }^{c}$ Institute for Superconducting \& Electronic Materials, University of 15 Wollongong, NSW 2500, Australia

$\dagger$ Electronic Supplementary Information (ESI) available: Experimental details and characterizations. See DOI: 10.1039/b000000x/

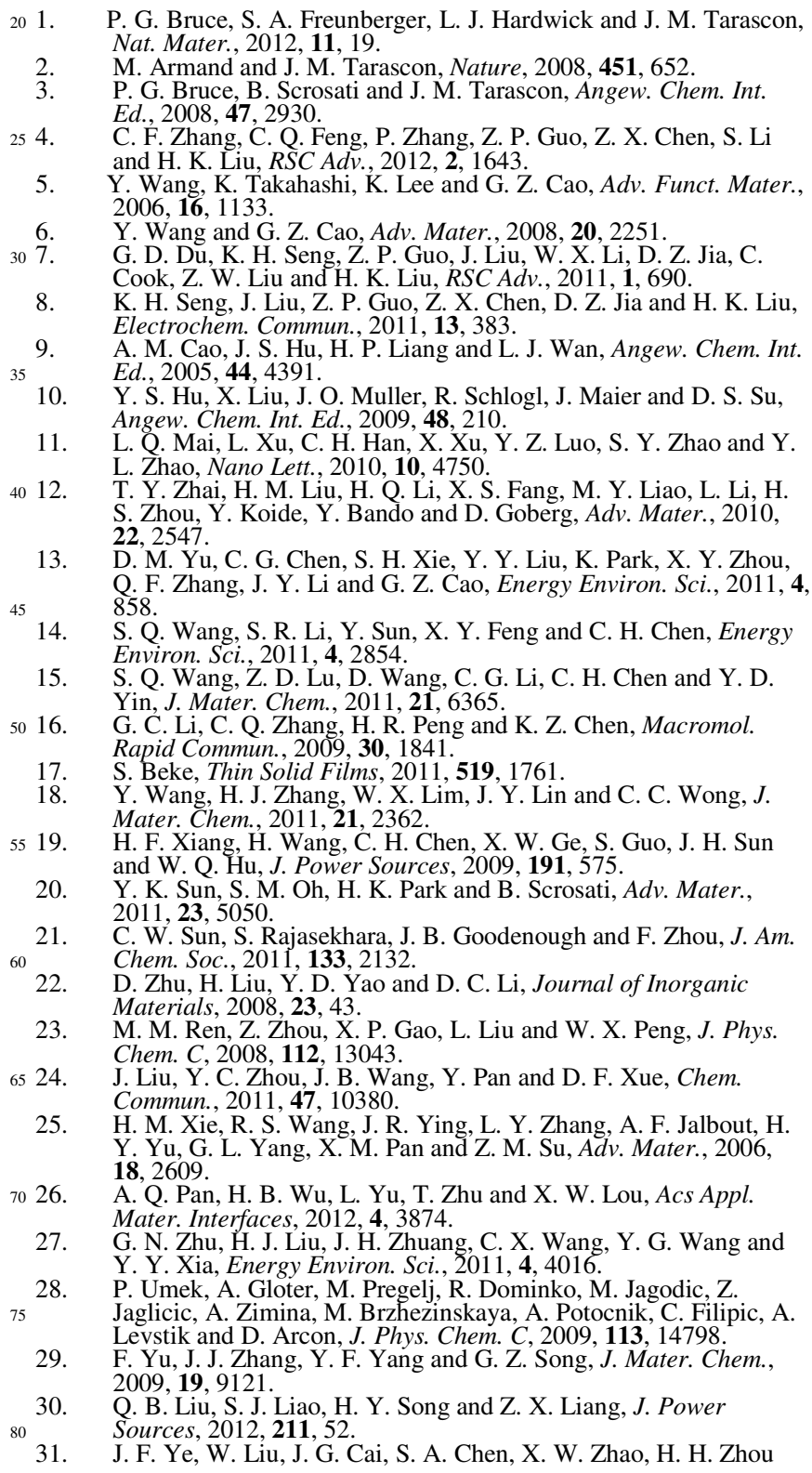

15. S. Q. Wang, Z. D. Lu, D. Wang, C. G. Li, C. H. Chen and Y. D. Yin, J. Mater. Chem., 2011, 21, 6365.

$5016 . \quad$ G. C. Li, C. Q. Zhang, H. R. Peng and K. Z. Chen, Macromol. Rapid Commun., 2009, 30, 1841 .

17. S. Beke, Thin Solid Films, 2011, 519, 1761.

18. Y. Wang, H. J. Zhang, W. X. Lim, J. Y. Lin and C. C. Wong, J. Mater. Chem., 2011, 21, 2362.

5519 . H. F. Xiang, H. Wang, C. H. Chen, X. W. Ge, S. Guo, J. H. Sun and W. Q. Hu, J. Power Sources, 2009, 191, 575.

20. Y. K. Sun, S. M. Oh, H. K. Park and B. Scrosati, Adv. Mater. 2011, 23, 5050

21. C. W. Sun, S. Rajasekhara, J. B. Goodenough and F. Zhou, J. Am.

60 Chem. Soc., 2011, 133, 2132.

22. D. Zhu, H. Liu, Y. D. Yao and D. C. Li, Journal of Inorganic Materials, 2008, 23, 43.

23. M. M. Ren, Z. Zhou, X. P. Gao, L. Liu and W. X. Peng, J. Phys. Chem. C, 2008, 112, 13043.

6524. J. Liu, Y. C. Zhou, J. B. Wang, Y. Pan and D. F. Xue, Chem. Commun., 2011, 47, 10380.

25. H. M. Xie, R. S. Wang, J. R. Ying, L. Y. Zhang, A. F. Jalbout, H. Y. Yu, G. L. Yang, X. M. Pan and Z. M. Su, Adv. Mater., 2006, 18, 2609.

7026. A. Q. Pan, H. B. Wu, L. Yu, T. Zhu and X. W. Lou, Acs Appl. Mater. Interfaces, 2012, 4, 3874.

27. G. N. Zhu, H. J. Liu, J. H. Zhuang, C. X. Wang, Y. G. Wang and Y. Y. Xia, Energy Environ. Sci., 2011, 4, 4016.

28. P. Umek, A. Gloter, M. Pregelj, R. Dominko, M. Jagodic, Z.

75 Jaglicic, A. Zimina, M. Brzhezinskaya, A. Potocnik, C. Filipic, A Levstik and D. Arcon, J. Phys. Chem. C, 2009, 113, 14798

29. F. Yu, J. J. Zhang, Y. F. Yang and G. Z. Song, J. Mater. Chem. 2009, 19, 9121

30. Q. B. Liu, S. J. Liao, H. Y. Song and Z. X. Liang, J. Power

80 Sources, 2012, 211, 52.

31. J. F. Ye, W. Liu, J. G. Cai, S. A. Chen, X. W. Zhao, H. H. Zhou

and L. M. Qi, J. Am. Chem. Soc., 2011, 133, 933.

32. H. Yang, X. L. Wu, M. H. Cao and Y. G. Guo, J. Phys. Chem. C $2009, \mathbf{1 1 3}, 3345$

85 33. Y. H. Xiao, S. J. Liu, F. Li, A. Q. Zhang, J. H. Zhao, S. M. Fang and D. Z. Jia, Adv. Funct. Mater., 2012, 22, 4052.

34. P. Nie, L. F. Shen, F. Zhang, L. Chen, H. F. Deng and X. G. Zhang, Crystengcomm, 2012, 14, 4284 .

35. T. Tao, A. M. Glushenkov, C. F. Zhang, H. Z. Zhang, D. Zhou, Z. 90 P. Guo, H. K. Liu, Q. Y. Chen, H. P. Hu and Y. Chen, J. Mater. Chem., 2011, 21, 9350.

36. Z. Y. Wang, D. Y. Luan, S. Madhavi, Y. Hu and X. W. Lou, Energy Environ. Sci., 2012, 5, 5252. 